\title{
Rape (Brassica chinensis L.) seed germination, seedling growth, and physiology in soil polluted with di-n-butyl phthalate and bis(2-ethylhexyl) phthalate
}

\author{
Tingting Ma $\cdot$ Peter Christie $\cdot$ Ying Teng $\cdot$ Yongming Luo
}

Received: 10 October 2012 / Accepted: 23 January 2013 / Published online: 7 February 2013

(C) Springer-Verlag Berlin Heidelberg 2013

\begin{abstract}
Phthalic acid esters (PAEs) pollution in agricultural soils caused by widely employed plastic products is becoming more and more widespread in China. PAEs polluted soil can lead to phytotoxicity in higher plants and potential health risks to human being. We evaluated the individual toxicity of di- $n$-butyl phthalate (DnBP) and bis (2-ethylhexyl) phthalate (DEHP), two representative PAEs, to sown rape (Brassica chinensis L.) seeds within $72 \mathrm{~h}$ (as germination stage) and seedlings after germination for 14 days by monitoring responses and trends of different biological parameters. No significant effects of six concentrations of PAE ranging from 0 (not treated/NT) to $500 \mathrm{mg}$ $\mathrm{kg}^{-1}$ on germination rate in soil were observed. However, root length, shoot length, and biomass (fresh weight) were inhibited by both pollutants (except root length and biomass under DEHP). Stimulatory effects of both target pollutants on malondialdehyde (MDA) content, superoxide dismutase (SODase) activity, ascorbate peroxidase (APXase) content, and polyphenoloxidase (PPOase) activity in shoots and
\end{abstract}

Responsible editor: Elena Maestri

T. Ma $\cdot$ Y. Teng $\cdot$ Y. Luo

Key Laboratory of Soil Environment and Pollution Remediation, Institute of Soil Science, Chinese Academy of Sciences,

Nanjing 210008, China

T. Ma $\cdot$ Y. Teng $\cdot$ Y. Luo

Graduate University of the Chinese Academy of Sciences,

Beijing 100049, China

P. Christie

Agri-Environment Branch, Agri-Food and Biosciences Institute,

Newforge Lane,

Belfast BT9 5PX, UK

Y. Luo $(\bowtie)$

Yantai Institute of Costal Zone Research,

Chinese Academy of Sciences, Yantai 264003, China

e-mail:ymluo@yic.ac.cn roots (SODase activity in shoots excluded) were in the same trend with the promotion of proline (Pro) but differed with acetylcholinesterase activity (except in shoots under DnBP) for analyzed samples treated for $72 \mathrm{~h}$ and 14 days. Responses of representative storage compounds free amino acids (FAA) and total soluble sugar (TSS) under both PAEs were raised. Sensitivity of APXase and Pro in roots demonstrates their possibility in estimation of PAE phytotoxicity and the higher toxicity of DnBP, which has also been approved by the morphological photos of seedlings at day 14 . Higher sensitivity of the roots was also observed. The recommended soil allowable concentration is $5 \mathrm{mg} \mathrm{DnBP} \mathrm{kg}^{-1}$ soil for the development of rape. We still need to know the phytotoxicity of DEHP at whole seedling stage for both the growing and development; on the other hand, soil criteria for PAE compounds are urgently required in China.

Keywords Phytotoxicity $\cdot$ Oxidative stress $\cdot$ PAEs $\cdot$ Rape (Brassica rapa) $\cdot$ Seed germination $\cdot$ Seedling growth

\section{Background, aims, and scope}

Phthalic acid ester (PAE) compounds are the most widely used plasticizers worldwide, also well-known as vital endocrine-disrupting chemicals (Chen et al. 2008; Wagner and Oehlmann 2009). There have been ubiquitous contaminations in every environmental matrix because of their weak binding forces with other components of environmental compartments (Blair et al. 2009). Di- $n$-butyl phthalate (DnBP) and bis(2-ethylhexyl) phthalate (DEHP), two representative PAEs in soils and sediments of China (Tan 1995; Wang et al. 2006; Liu et al. 2009b), are causing increasing concern because of their harmful effects on urease, phosphatase, catalase, microorganisms, animals, and the microbial community in contaminated soils (Chen et al. 2004; 
Gao and Chen 2008; Xie et al. 2009; Gao 2010). Phytotoxicity tests using higher plants are frequently employed for pollutants but there have been few such studies on PAEs. Investigations have shown that DnBP and DEHP in soil can decrease the vitamin $\mathrm{C}$ content in the fruit of peppers (Capsicum spp.) (An et al. 1999; Yin et al. 2002); significant accumulation and differences in expression of six protein spots in the leaf tissue of Chinese cabbage (Brassica rapa var. chinensis) have also been observed (Liao et al. 2009).

In agricultural soils, the main anthropogenic sources of PAEs are atmospheric from paint spraying, plastic garbage incineration, agricultural film plasticizers volatilization, industrial dusts sedimentation, sewage sludge and biosolids, chemical fertilizers, organic fertilizers and pesticides application, and rainwater leaching of piles of plastic waste ( $\mathrm{Li}$ et al. 2010; Guo and Kannan 2012). Soil concentrations of DnBP and DEHP have been reported to range from 2.75 to 29.37 and from 1.15 to $7.99 \mathrm{mgkg}^{-1}$, respectively (Xu et al. 2008). Concentrations of DnBP and DEHP in vegetables sold in Guangzhou, South China are around 4.72 and $4.98 \mathrm{mg} \mathrm{kg}^{-1}$ respectively, and in the Pearl River Delta, it is between 0.07 and $11.22 \mathrm{mg} \mathrm{kg}^{-1}$ for the sum of DnBP and DEHP (Cai et al. 2003; Zeng et al. 2005, 2006). Six PAE compounds have been nominated by US Environmental Protection Agency (US EPA) as priority pollutants, and DnBP has been ranked by the European Union as a priority pollutant. PAEs may induce cancer and gene mutations after long-term contact at low concentrations and may be transferred from contaminated soils and crops to the human food chain, leading to considerable public concern (Hu et al. 2007).

The germination and prime seedling stages are considered crucial for the subsequent vegetative and reproductive growth of higher plants. They have developed an efficient anti-oxidant defense system that helps them to survive under adverse environmental conditions (Mishra et al. 1993). In plants, malondialdehyde (MDA) formation describes the oxidative stress caused by lipid peroxidation (DionisioSese and Tobita 1998); superoxide dismutase (SODase) is the most valuable compound in the protective system of higher plants to survive oxidative stress (Asada and Takahashi 1987; Schoner and Krause 1990), and this constituent has long been used in the assessment of environmental toxicity (Mishra et al. 1993); ascorbate peroxidase (APXase) is one of the two major scavengers that control of excessive levels of $\mathrm{H}_{2} \mathrm{O}_{2}$ (Wang et al. 2010); polyphenoloxidase (PPOase) could be important for the induced defense of plants (Constabel and Ryan 1998); acetylcholinesterase (AChEase) alternation could indicate the contamination of environment (Ferreira et al. 2006); free proline (Pro) content could also be considered a biomarker of organic pollution (Qu et al. 2006). Short-term effects of pollutants on initial growth (germination, root elongation, shoot elongation, and biomass), anti-oxidase activity, critical amino acids, such as total amino acid (free amino acids (FAA); more commonly utilized in the demonstration of crop quality) and storage compounds, such as total soluble sugar (TSS) have been investigated in representative model crops for the assessment of target pollutants. Subchronic toxicity test were also conducted to check the relatively longer exposure damage of target pollutants and the reliability of sensitive indicators. Rape (B. rapa) has been selected following the recommendation of Organization for Economic Cooperation and Development (1984) and US EPA (Fletcher et al. 1985) for the separate phytotoxicity testing of DnBP and DEHP.

In the present study, prediction of the potential toxicity of DnBP and DEHP on rape seedlings (at 3 and 14 days after sowing) was determined using a range of physiological tests, and the recommended allowable soil concentrations were also proposed for the pollutant with higher toxicity.

\section{Materials and methods}

\section{Chemicals and reagents}

DnBP (99.1\%) and DEHP (99.6 \%) were obtained from AccuStandard ${ }^{\circledR}$, Inc., New Haven, CT. Nitro blue tetrazolium (NBT), ascorbic acid (AsA), trichloroacetic acid (TCA), thiobarbituric acid (TBA), Pro, alanine, sulfosalicylic acid, ninhydrin, catechol, anthrone, polyvinylpyrrolidone (PVP), monosodium orthophosphate $\left(\mathrm{NaH}_{2} \mathrm{PO}_{4}\right)$, disodium hydrogen phosphate $\left(\mathrm{Na}_{2} \mathrm{HPO}_{4}\right)$, hydrogen peroxide $\left(\mathrm{H}_{2} \mathrm{O}_{2}\right)$, o-methoxyphenol, riboflavin, EDTA- $\mathrm{Na}_{2}$, sodium hydroxide, glacial acetic acid, and acetone used in the tests were all analytical reagents purchased from the National Pharmaceutical Group Chemical Reagent Co., Ltd., Shanghai. Catalog number A204 for AChEase assay kits were purchased from Jiancheng Bioengineering Institute, Nanjing, China.

\section{Soil preparation}

The test soil consisted of the surface layer (top $20 \mathrm{~cm}$ of the soil profile) of an uncontaminated area at Qixia, Nanjing, China, and is classified as an Alfisol (soil with more clayey and fine particulates, brownish reddish, and more calcium) according to the US Department of Agriculture (US DA 2011) classification system. The soil $\mathrm{pH}$ was 7.4 , with $1.67 \%$ clay, $6.22 \%$ silt, $2.11 \%$ sand, $14.6 \%$ organic matter, and available nitrogen, phosphorus, and potassium concentrations of $96.8,14.4$, and $102.8 \%$, respectively. Soil was passed through a 2-mm sieve before use and the background concentrations of the two target pollutants were 
determined to be $142.6 \pm 4.19 \mu \mathrm{g}$ DnBP and $194.5 \pm 1.09 \mu \mathrm{g}$ DEHP kg ${ }^{-1}$ soil (oven dry basis).

For acute toxicity test, batches of soil $(250 \mathrm{~g} \times 4)$ were adjusted to concentrations of DnBP or DEHP of $0,1,5,20$, 100 , and $500 \mathrm{mg} \mathrm{kg}^{-1}$ soil by spraying with stock solutions in acetone $(5 \mathrm{ml})$. For subchronic toxicity test, pots of soil $(2.5 \mathrm{~kg} \times 4)$ were adjusted to concentrations of DnBP or DEHP of $0,1,5,20,100$, and $500 \mathrm{mg} \mathrm{kg}^{-1}$ soil by spraying with stock solutions in acetone $(50 \mathrm{ml})$. The same volumes of pure acetone without PAE pollutants were sprayed on every not treated (NT) soil sample in each toxicity test group. After evaporation of acetone, the soils were mixed thoroughly and the soil moisture was amended to $70-75 \%$ (60\% of water holding capacity) before use.

\section{Plant inhibition experiment}

Seeds of rape (B. chinensis L.) recommended by the Organization for Economic Co-operation and Development (1984) as a test species in terrestrial environmental assessment were obtained from the Chinese Academy of Agricultural Sciences. Seeds were stored in a refrigerator at $4{ }^{\circ} \mathrm{C}$ before use. Seeds were surface sterilized by immersion in $10 \%$ sodium hypochlorite solution for 10 min (US EPA 1996), rinsed three times with deionized water, soaked in deionized water for $2 \mathrm{~h}$, and finally sown in the prepared soils. Plastic equipment was avoided throughout the procedure to eliminate PAE background contamination. All the glass Petri dishes were washed and baked in an oven at $400{ }^{\circ} \mathrm{C}$ before use (Ma et al. 2012).

For acute toxicity test, $250 \mathrm{~g}$ of test soil spiked with different concentrations of DnBP or DEHP were placed in $150 \times 20 \mathrm{~mm}$ glass Petri dishes. Four replicates of each treatment were set up and 50 pretreated soaking seeds of uniform size were sown with equal spacing in each Petri dish. The dishes were covered, sealed with tape and placed in the dark in a growth chamber at $25 \pm 1^{\circ} \mathrm{C}$ for $72 \mathrm{~h}$ before the germination test was halted. The germination status of each treatment was checked, seedling root and shoot lengths were measured, and the biomass in each dish was determined by fresh weight (FW). Root length was defined as the length from root tip to root radicle. Seeds were considered to have germinated when the root length was $>5 \mathrm{~mm}$ (Wang et al. 2001), and subchronic toxicity test, $2.5 \mathrm{~kg}$ of test soil spiked with different concentrations of DnBP or DEHP were placed in $25 \times 10 \mathrm{~cm}$ straw pressing pots. Four replicates of each treatment were set up and 25 germinated seedlings of uniform height were transplanted with equal spacing in pots and cultivated under the same chamber condition as before. After 11 days, root and shoot were also harvested after photographing for the analysis of selected sensitive parameters.
Determination of enzymes and critical compounds in plant defense mechanism

All analyses were performed on seedling of shoots and roots of days 3 and 14 separately. Excess induced oxidative damage was estimated by measuring MDA levels. About $0.5 \mathrm{~g}$ of fresh sample was homogenized in $5 \mathrm{ml}$ of $0.1 \%(w / v)$ TCA solution. After centrifugation (15 min, 6,000 rpm), $2 \mathrm{ml}$ of the supernatant was added to $2 \mathrm{ml} 0.5 \%$ TBA in $20 \%$ TCA and heated in a boiling water bath for $30 \mathrm{~min}$. After fast cooling on ice the mixture was centrifuged at $6,000 \mathrm{rpm}$ for $5 \mathrm{~min}$. The absorbance of the supernatant at 532 and $600 \mathrm{~nm}$ was read to calculate the MDA content (Amor et al. 2005).

Fresh samples of about $0.5 \mathrm{~g}$ were ground in a mortar to extract with ice-cold $50 \mathrm{mM}$ potassium phosphate-buffered saline (PBS; $\mathrm{pH} 7.8$ ). The homogenates were centrifuged at $6,000 \mathrm{rpm}$ at $4{ }^{\circ} \mathrm{C}$ for $20 \mathrm{~min}$ and the supernatant was collected for SODase assay, following the method of Giannopolitis and Ries (1977) by measuring its ability to inhibit the photochemical reduction of NBT. One unit of SODase activity is defined as the amount of enzyme inhibiting $50 \%$ of the initial reduction of NBT under light. The enzymatic activity was expressed as units (U) per milligram $\mathrm{FW}$.

The same enzyme extraction method was used as for SODase and APXase assay, except for $\mathrm{pH}$ condition of PBS buffer ( $\mathrm{pH} 7.0$ ), was performed using the method of Koricheva et al. (1997) in which the $3 \mathrm{ml}$ of reaction mixture consisted of $50 \mathrm{mM}$ PBS (pH 7.0), $0.3 \mathrm{mM}$ AsA, $0.06 \mathrm{mM} \mathrm{H}_{2} \mathrm{O}_{2}, 0.1 \mathrm{mM}$ EDTA, and $0.1 \mathrm{ml}$ enzyme (sample). The reaction was initiated by the addition of $\mathrm{H}_{2} \mathrm{O}_{2}$ and the decrease in absorbance at $290 \mathrm{~nm}$ within $30 \mathrm{~s}$ was measured with a UV spectrophotometer.

PPOases are enzymes that catalyze the $\mathrm{O}_{2}$-dependent oxidation of monophenols or o-diphenols. Fresh plant material was ground in a mortar with ice-cold 0.1 M PBS buffer (pH 7.8) containing $1 \%$ solid PVP. After centrifugation at $15,000 \times g$ for $15 \mathrm{~min}$ at $4{ }^{\circ} \mathrm{C}$, the supernatant was used for the PPOase assays. The reaction was initiated by the addition of $30 \mu \mathrm{M}$ of catechol. PPOase activity was measured by the disappearance of catechol spectrophotometrically at $525 \mathrm{~nm}$ every $30 \mathrm{~s}$ for $5 \mathrm{~min}$ at $25^{\circ} \mathrm{C}$.

Both analyses were performed on seedling shoots and roots. The instructions for the AChEase assay kit were followed (Nwosu et al. 1992) based on the principle that acetyl cholinesterase can hydrolyze acetylcholine to acetic acid and choline and produce yellow trinitrobenzene in the presence of thiol reagent. AChEase activity was quantified by colorimetry by production of a yellow compound at $412 \mathrm{~nm}$. Pro content was determined by the method of $\mathrm{Li}$ et al. (1995) with modification to expand the test weight and volume in proportion. 
A fresh sample of about $0.5 \mathrm{~g}$ was homogenized with $5 \mathrm{ml}$ of $3 \%$ sulphosalicylic acid before incubation at $100{ }^{\circ} \mathrm{C}$ for $10 \mathrm{~min}$. Then $2 \mathrm{ml}$ of the supernatant was added to a mixture of $2 \mathrm{ml}$ of glacial acetic and $2 \mathrm{ml}$ of $2.5 \%(w / v)$ acidic ninhydrin before boiling at $100{ }^{\circ} \mathrm{C}$ for a further $25 \mathrm{~min}$. After the solution was cooled, $5 \mathrm{ml}$ of toluene was added for extraction, prior to reading the absorbance of the upper red layer (toluene) at $520 \mathrm{~nm}$ and calculating the content of Pro (in milligrams per gram FW).

\section{Determination of storage compounds (FAA and TSS)}

Both FAA and TSS were analyzed on the whole harvested seedlings. FAA content was estimated following the method of Shukla et al. (2002) with minor modifications to expand the test weight and volume in proportion. Fifty milligrams of ice-water bath ground fresh sample was stirred in $5 \mathrm{ml}$ $10 \%$ acetic acid $(v / v)$ solution overnight and distilled water was added to adjust the total volume to $50 \mathrm{ml}$. After filtration, $2 \mathrm{ml}$ of the extract, $3 \mathrm{ml} 1 \%$ ninhydrin (in $0.5 \mathrm{M}$ citrate buffer, $\mathrm{pH} 5.5$ ) and $0.1 \mathrm{ml} 1 \%$ ascorbic acid were added and mixed before heating in a boiling water bath for $15 \mathrm{~min}$. After cooling, FAA content was determined by the absorbance at $570 \mathrm{~nm}$. Alanine was used as the FAA standard.

TSS content was estimated according to Moya et al. (1993) with slight modification. Eighty milliliters of $80 \%$ ethanol was added to $1.0 \mathrm{~g}$ of fresh sample and extracted in a water bath at $80^{\circ} \mathrm{C}$ for $30 \mathrm{~min}$. The extraction was repeated twice and the mixture was centrifuged at $12,000 \times \mathrm{g}$ for $10 \mathrm{~min}$. All the supernatants were combined and made up to a final volume of $25 \mathrm{ml}$ with $80 \%$ ethanol. Ten-milliliter extract was steamed to dry over a boiling water bath; $0.5 \mathrm{ml}$ of $\mathrm{H}_{2} \mathrm{SO}_{4}$-anthrone reagent was added and the TSS content was determined by spectrophotometry at $620 \mathrm{~nm}$. Glucose was used as the standard for quantification.

\section{Data analysis}

The fifty percent inhibitory concentration $\left(\mathrm{IC}_{50}\right)$ values of the different parameters were calculated using the SPSS v.14.0 software package (Sundarammal et al. 2012). All results are presented as mean values \pm standard error (SE) of four replicates with 50 seeds each (for both growth and biochemical assays). One-way analysis of variance was used to assess significant differences with a $p$ value less than 0.05 .

\section{Results}

Effects of DnBP and DEHP on germination and growth

Little effect of either pollutant was observed on the germination rate of rape after incubation for $72 \mathrm{~h}$, even at the highest concentration studied $\left(500 \mathrm{mgkg}^{-1}\right.$ soil $)$ (Table 1). In contrast, inhibition of root elongation, shoot elongation, and biomass in seedlings exposed to DnBP were more apparent (but not root elongation and biomass when exposed to DEHP). Among all the estimated growth parameters, root elongation may be considered the most sensitive physical parameter with the lowest $\mathrm{IC}_{50}$ under exposure to $\mathrm{DnBP}$, with a value of $<500 \mathrm{mgkg}^{-1}$ soil, and with less sensitivity to DEHP $\left(<1,500 \mathrm{mgkg}^{-1}\right.$ soil $)$.

\section{Effects of DnBP and DEHP in acute toxicity test}

As shown in Fig. 1a, compared with the NT, all doses of both pollutants (and especially, $>5 \mathrm{mg} \mathrm{kg}^{-1}$ ), showed significant positive effects on the MDA content of roots but there were only small negative effects on the shoots which became significant at $100 \mathrm{mgkg}^{-1}$ under DEHP. SODase (Fig. 1b) showed similar trends in the roots and inhibition in the shoots under DEHP treatment. The APXase activity responses (Fig. 1c) in both roots and shoots were positive except at $1 \mathrm{mgkg}^{-1}$ DEHP and $5 \mathrm{mgkg}^{-1} \mathrm{DnBP}$ in the shoots. Both DnBP and DEHP were associated with significant increases in PPOase (Fig. 1d) in both roots and shoots except at $20 \mathrm{mgkg}^{-1}$, but exposure to DnBP led to more PPOase activity than DEHP when the concentrations of the target pollutants were relatively high $\left(>100 \mathrm{mgkg}^{-1}\right.$ soil). Figure 1e shows that AChEase activity was lowered after DnBP treatment in both shoots and roots. However, DEHP appeared to stimulate activity in the shoots and inhibit AChEase in the roots. Pro accumulated in the shoots except at 1 and $5 \mathrm{mgkg}^{-1}$ DnBP (Fig. 1f). There was a slight tendency for Pro accumulation to decline in roots at higher DnBP concentrations. The contents of FAA and TSS were all significantly higher with exposure to both target pollutants except for only a slight increase FAA and TSS in roots (Fig. 2).

Effects of DnBP and DEHP in sub-chronic toxicity test

Photos of rape seedlings under treatment of 0,5 , and $10 \mathrm{mg}$ $\mathrm{kg}^{-1}$ DnBP and DEHP for 14 days reveal the severe exterior change of rape seedlings under the treatment of DnBP (at $10 \mathrm{mgkg}^{-1}$ so that the withered seedlings could not be harvested) and the stable look of seedlings under DEHP (Fig. 3). APXase and Pro were selected for further verifying of their sensitivity to DnBP and DEHP (Fig. 4), and compared with the NT, samples under the treatment of 5 and $10 \mathrm{mg} \mathrm{kg}^{-1}$ of both pollutants showed significant positive increase for APXase and Pro. Especially at $10 \mathrm{mg} \mathrm{kg}^{-1}$, seedlings of rapes were so withered that the seedlings were hard to collect and the two sensitive parameters could not be analyzed. 
Table 1 Dose-dependence linear regression fitting of two PAE compounds on growth of rape seedlings in test soil

\begin{tabular}{lllllll}
\hline Compound & End point & \multicolumn{2}{l}{ Regression parameter } & \multirow{2}{*}{$\mathrm{IC}_{50}\left(\mathrm{mgkg}^{-1}\right)$} \\
\cline { 3 - 6 } & & $a$ & $b$ & $R$ & $P$ value & \\
\hline \multirow{2}{*}{ DnBP } & Germination rate & -0.0026 & 96.24 & 0.5002 & 0.1372 & 38,621 \\
& Shoot elongation & -0.0003 & 0.0533 & 0.9973 & 0.0227 & 1,489 \\
& Root elongation & -0.0005 & 0.2673 & 0.9412 & 0.0389 & 465.4 \\
& Biomass & -0.0001 & 0.1323 & 0.9467 & 0.0416 & 3,677 \\
\multirow{2}{*}{ DEHP } & Germination rate & -0.0016 & 96.25 & 0.5398 & 0.1525 & 5,9843 \\
& Shoot elongation & -0.0002 & 0.0973 & 0.8866 & 0.0489 & 2,014 \\
& Root elongation & 0.0004 & -0.0705 & 0.8973 & 0.0462 & 1,426 \\
& Biomass & 0.0001 & 0.1233 & 0.9982 & 0.0337 & 3,767
\end{tabular}

Each point is the mean of 200 seeds. Significant differences are defined as $p<0.05$ growth. In addition, the lower $\mathrm{IC}_{50}$ of $\mathrm{DnBP}$ to root elongation indicates a higher toxicity to rape seedlings during the initial growth stages. However, rape produces a family of plant hormone compounds named brassinosteroids which play an important regulatory role in root elongation, shoot elongation, and the development of other organs (Yokota 1997). Also as a kind of ester, DEHP may have put on similar positive effects on roots and biomass of test plant, which may be viewed as mimicking the effects of plant hormones. In the roots the initial increase in MDA was followed by a decline at the highest dose/s, which also occurred in response to SODase. This may indicate some weakness in the antioxidant defense system.

\section{Effects on antioxidase and critical compounds at $72 \mathrm{~h}$}

Inhibition of MDA content when exposed to DnBP at concentrations of $>5 \mathrm{mg} \mathrm{kg}^{-1}$ indicates both the sensitivity of
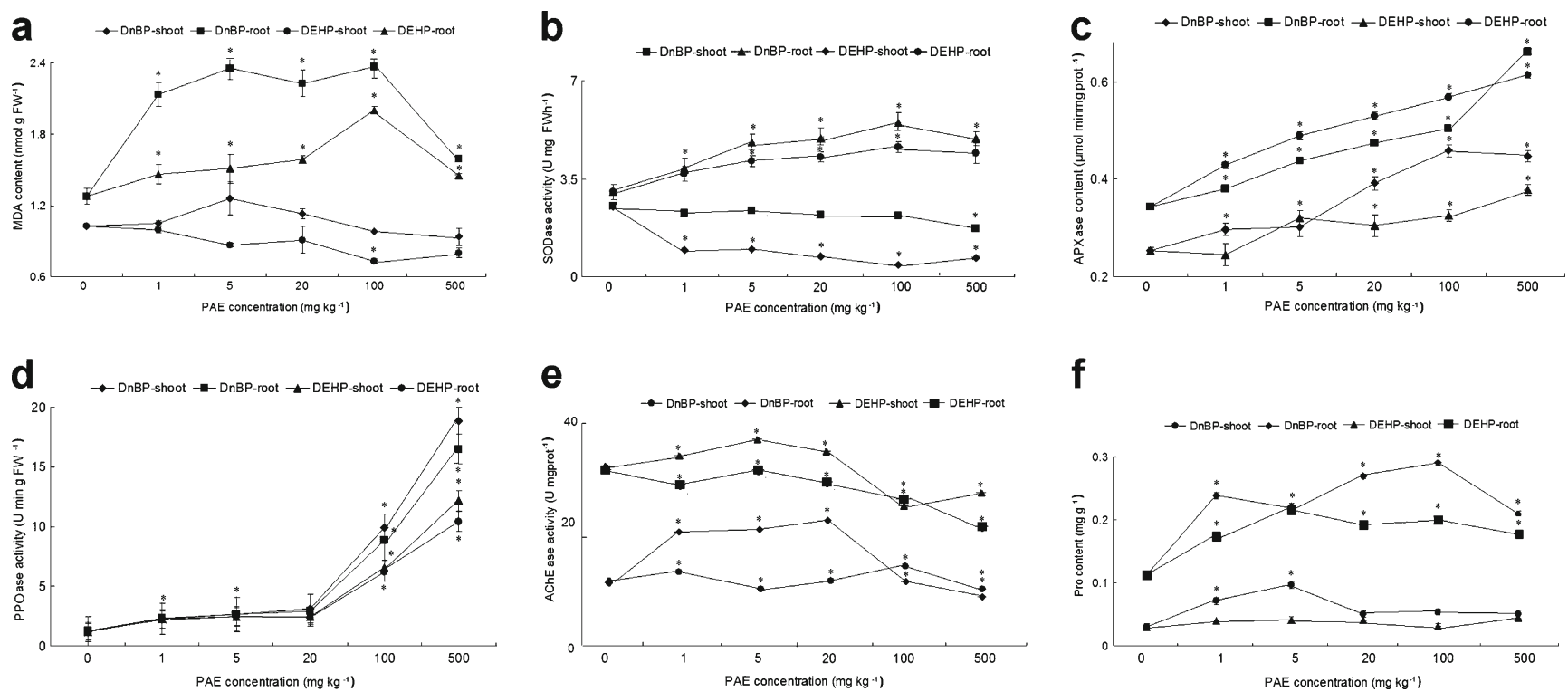

Fig. 1 MDA content, SODase activity, APXase content, PPOase activity, AChEase activity, and Pro content of rape shoots and roots after germination for $72 \mathrm{~h}$ under $0(N T), 1,5,20,100$, and $500 \mathrm{mgkg}^{-1}$ of DnBP and DEHP. a MDA content, b SODase activity, c APXase content, $\mathbf{d}$ PPOase activity, $\mathbf{e}$ AChEase activity, and $\mathbf{f}$ Pro content. Each point is the mean of four replicates from four Petri dishes. Bars are SE and asterisks denote significant differences from NT 


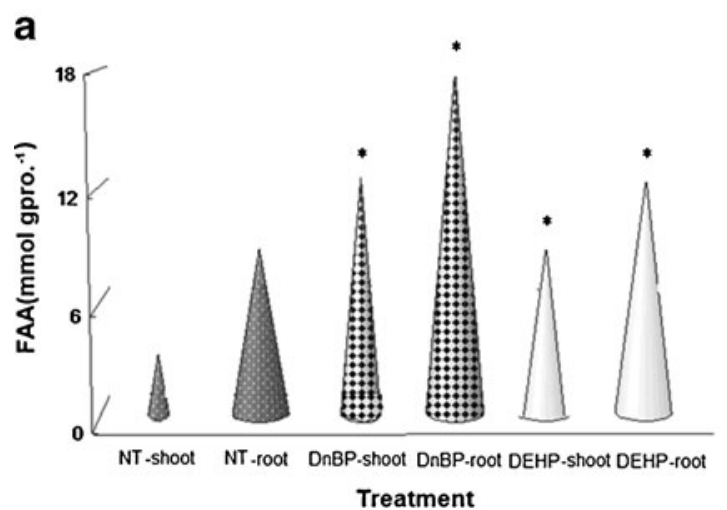

Fig. 2 Mean FAA and TSS contents of rape shoots and roots under treatment of $500 \mathrm{mgkg}^{-1} \mathrm{DnBP}$ and DEHP after germination for $72 \mathrm{~h}$. a FAA and $\mathbf{b}$ TSS contents. Each point is the mean of four replicates

the roots and the higher toxicity of DnBP compared with DEHP. Antioxidant enzymes and certain inducible metabolites in oxidative stress play a vital role in the adaption and ultimate survival of plants under stress conditions. Generally, the formation of MDA in plants reflects the oxidative stress as the result of lipid peroxidation. Usually, an increase in MDA content exhibits protective mechanisms and the consumption of MDA indicates slight damage to plant organs. An increase in MDA in the root indicates their sensitivity compared with the shoots and is also due to direct contact between the roots and pollutants in the soil. MDA in the shoots may require longer exposure times before it responds to the PAE.

Antioxidant status is an indicator of physiological equilibrium and is critically important for understanding the responses of organisms to contaminated environments. In particular, increases in SODase in plant roots at concentrations of DnBP at $>5 \mathrm{mgkg}^{-1}$ are important. SODase is extremely important antioxidant enzymes in the understanding of stress response mechanisms in cells in connection with the production of reactive oxygen species. A decline in

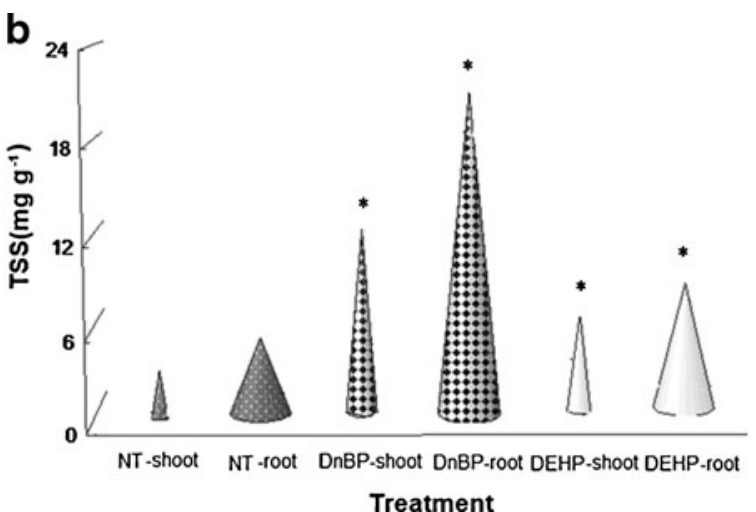

from four Petri dishes. Bars are SE and asterisks denote significant differences from NT

SODase activity in the aboveground parts indicates a higher adaptability in adverse conditions. Anti-oxidation and detoxification are the first line of defense to environmental stress (Wilhelm 2007), but increasing pollutant concentrations may lead to the breakdown of these processes and the stimulation of other relevant responses (Zhou et al. 2010). Reduced levels of SODase activity indicate a loss of protective capacity against cellular superoxide toxicity which might be caused by consumption of SODase over the short term and result in a transient shortage of SODase.

The trend in APXase activity represents the NT of excessive levels of $\mathrm{H}_{2} \mathrm{O}_{2}$ in the test plants because APXase is one of the two major scavengers of $\mathrm{H}_{2} \mathrm{O}_{2}$. APXase is present throughout the cell and has high substrate affinity when ascorbate acts as a reductant. The increase in APXase activity in the roots does not agree with the other reports on heavy metal stress in which leaves have been shown to produce more APXase than roots (Zhang et al. 2008; Zhang et al. 2010) but is in accord with our earlier conclusion that roots were more sensitive than shoots. Moreover, during germination APXase plays an important role in
Fig. 3 Photos of rape seedlings under treatment of 0,5 , and $10 \mathrm{mg} \mathrm{kg}^{-1}$ DnBP and DEHP for 14 days. Each photo stands for the general status of four replicate pots
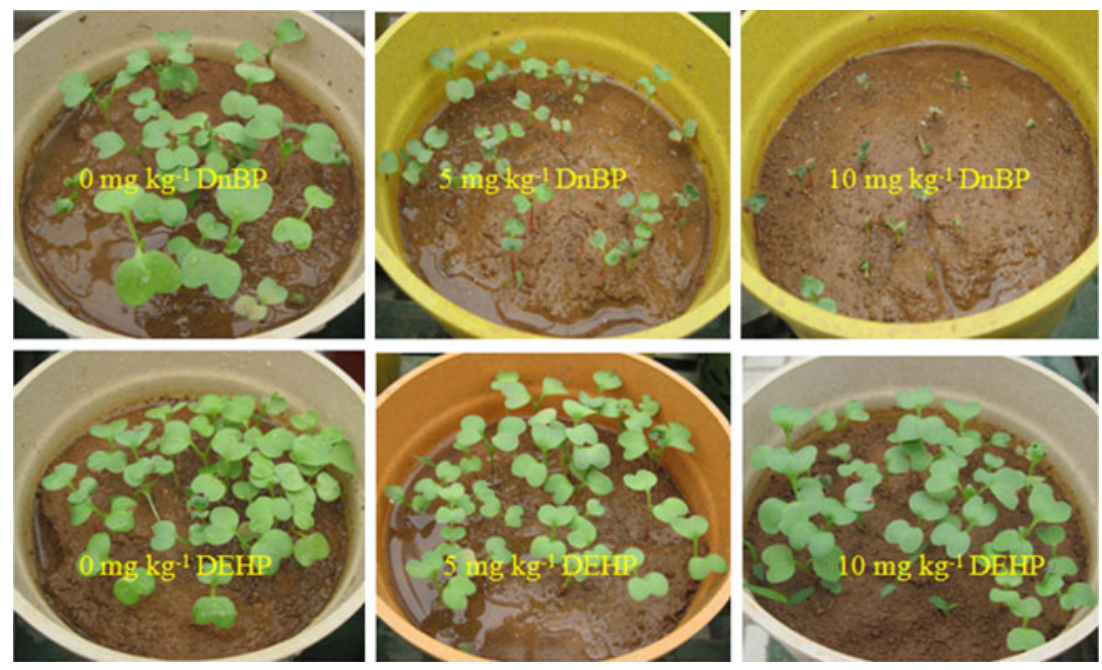


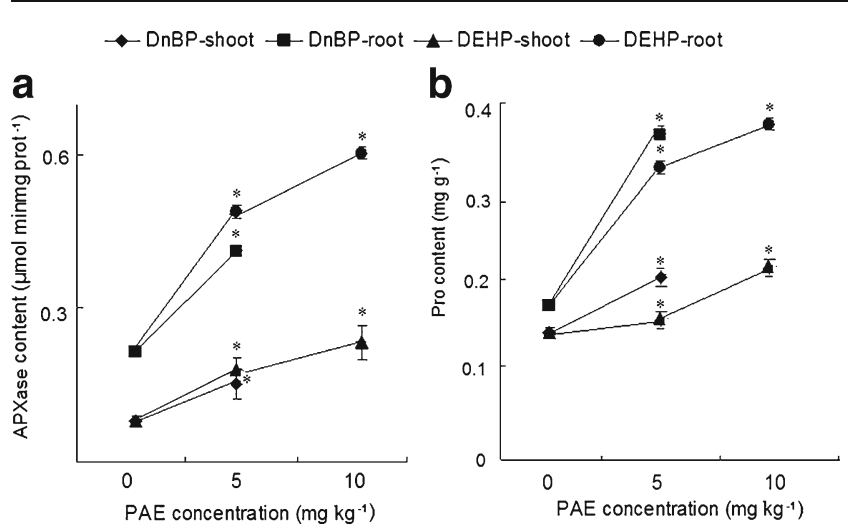

Fig. 4 APXase content and Pro content of rape seedling shoots and roots after germination for 14 days under $0(\mathrm{NT}), 5$, and $10 \mathrm{mgkg}^{-1}$ of DnBP and DEHP. a APXase and b Pro contents. Each point is the mean of four replicates from four pots. Bars are SE and asterisks denote significant differences from NT. The data of rape treated with DnBP under $10 \mathrm{mgkg}^{-1}$ are omitted because the seedling withered at day 14, which is proved by photos in Fig. 3

avoidance of $\mathrm{H}_{2} \mathrm{O}_{2}$ toxicity and the roots may possess a higher capacity to scavenge excess $\mathrm{H}_{2} \mathrm{O}_{2}$ during contact with contaminated soil. The sensitive reaction of APXase in root of the rape, under the treatment of $1 \mathrm{mgkg}^{-1}$ of DnBP or DEHP, entitles its recommendation as a biological indicator.

It has been over a century since the first report on catechol oxides as PPOases in plants (Bertrand 1896), but their specific functions have not been well explained until recently. However, their important roles as plant protection products (Constabel and Ryan 1998) have been widely accepted. Plants can accelerate PPOase activity as a defense against both biotic and abiotic stresses (Kwak et al. 1996). PPOases are documented to be defense-related proteins in tomato plants submitted to either wounding and/or to methyl jasmonate (MeJa) vapour treatment (Constabel et al. 1995). In the present study the induction of PPOase in rape was especially high in the shoots compared with the roots, and this is not in agreement with the common assumptions that roots are more sensitive than shoots due to the higher content of PPOases in both chloroplasts and mitochondria.

Biomarkers represent changes from the molecular to the organism level related to toxic effects of and/or exposure to contaminants. Moreover, responses of biomarkers appear prior to large variation in population and community levels and this is why they are employed as predictors of toxicity. AChEase has been used as a biomarker to assess the impact of heavy metal pollution in animal studies (Tsangaris et al. 2007), and it has been extracted from different plant species to treat human disease (Ingkaninan et al. 2003; Ferreira et al. 2006). The trends in Fig. 1e show that AChEase activity in both roots and shoots of rape exposed to both target pollutants was inhibited, especially in the roots at all PAE concentrations tested. High levels of AChEase inhibitory activity usually appear in contaminated environments (Ferreira et al. 2006), but during the germination period AChEase is also bound up with the germination of seeds. The supplementary role of AChEase in seed germination is promotion of photophilous plants and restriction of nonphotophilous plants. Rape does not require light during germination, and a decline in AChEase in shoots and roots is consistent with the characteristic of rape, which indicated a lack of effect of both target pollutants on germination rate. The role of AChEase and its responses in plants growth need elucidating under contaminated environment.

The Pro content of plants was formerly considered to act as a response to climatic change (Treichel et al. 1984) and heavy metal contamination (Rai et al. 2004; Sharma et al. 2005). Effects of organic pollutants such as pesticides on the free Pro content in Euonymus japonica also suggested a substantially increased free Pro content after pesticide application for 10 days (Qu et al. 2006). The stimulation of Pro content under both pollutants (Fig. 1f) over all treatments is in accordance with earlier studies on plants under adverse conditions. Under normal conditions the free Pro content in plants is relatively low. However, when drought, cold or high salinity occurs, the content of free Pro can increase substantially. The accumulation of Pro can be attributed to an enhancement of Pro synthesis, an inhibition of Pro oxidation or a decline in total protein synthesis accompanying the inhibition of Pro synthesis (Wong 2000). Pro can protect plant cells from adverse conditions by maintaining the integrity of cell membranes and preventing water loss from the cells (Zhang et al. 2003). Lower accumulation of Pro in the shoots of rape under DEHP may indicate the lower toxicity of this PAE compound (Fig. 1f). Both APXase and Pro in root are recommended as the most sensitive bio-indicators of rape under treatment of both DnBP and DEHP for their significant reaction at $1 \mathrm{mgkg}^{-1}$ pollution level.

Effects on storage compounds at $72 \mathrm{~h}$

The stimulation of FAA content and TSS content agrees with earlier investigations. Low levels of the herbicide trifluralin induced the elevation of free amino acids in melon seedlings (Starratt and Lazarovits 1999). TSS was also induced under drought, salinity and low temperatures and was often accompanied by increases in both FAA and Pro (Ren et al. 2001; Xu et al. 2001; Liu et al. 2007). Roots are believed to be classic reserve organs but much higher concentrations of storage compounds were observed in rape shoots (Fig. 2). One possible explanation is the increase in biomass because the shoots developed more rapidly than the roots.

In addition to the parameters monitored in this experiment, the transfer of target pollutants to test plants, which 
has so much to do with the physical characteristics of compounds, may also significantly affect the expression of their toxicity. The internal relationship between accumulation of PAE target pollutants in plants and their phytotoxicity in longer-term studies beyond the seedling stage still requires further study.

Effects on seedling growth and sensitive compounds at 14 days

Photos of rape seedlings under treatment of 0,5 , and $10 \mathrm{mg}$ $\mathrm{kg}^{-1}$ DnBP and DEHP for 14 days indicated the higher toxicity of DnBP to rape at $5 \mathrm{mgkg}^{-1}$, which could also be proved by the reaction of two sensitive parameters that both APXase and Pro content were significantly increased. Seriously withering of leaf margins have also been recognized which indicated the serious damage caused by DnBP to rape seedlings. In other documents, the appearance of leaf withered means severe trauma of plant growth mainly caused by environmental abnormal. Strong environmental pressure from metal contamination, like cadmium, $\mathrm{Cr}^{6+}$, could result in both withering of leaves, root stock rotted, and intensification of metal detoxification processes (Pielichowska and Wierzbicka 2004; Szarek-Łukaszewska et al. 2004; Han and $\mathrm{Hu}$ 2005). NaF-treated plants showed alteration like withered appearance of the leaf tip within $24 \mathrm{~h}$, then tissues color change extended to leaf vein, and the appearance looked very like early frost injury, which absolutely suggest interior injury of plant (Fornasiero 2001). Chilling could increase the percentage of leaves that withered and the levels of $\mathrm{H}_{2} \mathrm{O}_{2}, \mathrm{O}_{2}{ }^{--}$, and MDA in cucumber leaves under low light (Liu et al. 2009a), which is similar with the appearance of rape seedling leaves in this experiment. However, the alternation caused by target DEHP was still acceptable for seedlings no matter judging by the leaves or by sensitive parameters. Soil allowable concentration threshold should be proposed to DnBP based on more investigated data of its ecotoxicity effects, especially in China, where the contamination of DnBP in soil is more and more frequently discovered.

\section{Conclusions}

DnBP appeared to show higher phytotoxicity than DEHP in our testing of the target plants. Higher sensitivity of the roots was also observed. Although neither of the target pollutants led to severe inhibition of seed germination, effects on initial growth parameters, especially of the roots, were observed. Antioxidant enzyme responses and elevation of Pro, FAA, and TSS at $72 \mathrm{~h}$ and photos at 14 days confirm this result, and $5 \mathrm{mgkg}^{-1}$ can be recommended as the allowable concentration of DnBP in soil. APXase and Pro in the roots of rape are recommended and proved as biological indicators because of their sensitivity when subjected to DnBP and DEHP. Other plant species recommended such as wheat with higher sensitivity should be included in further investigations of the phytotoxicity of PAE compounds to confirm the results using rape and refine the recommended allowable limits of soil PAEs.

Acknowledgment This research was supported by the National Environmental Protection Special Funds for Scientific Research on Public Causes of China (201109018 and 2010467016).

\section{References}

Amor NB, Hamed KB, Debez A, Grignonb C, Abdelly C (2005) Physiological and antioxidant responses of the perennial halophyte Crithmum maritimum to salinity. Plant Sci 168:889-899

An Q, Jin W, Li Y, Xu RW (1999) Influence of plasticizers PAEs to the soil-plant system. Acta Pedol Sin 2:118-126

Asada K, Takahashi M (1987) Production and scavenging of active oxygen in photosynthesis. In: Kyle DJ, Osmond CB, Amtzen CJ (eds) Photoinhibition. Elsevier, Amsterdam, pp 227-287

Bertrand G (1896) Sur une nouvelle oxydase, ou ferment soluble oxidant, d'origine végétale. CR Acad Sci (Paris) 122:1215-1217

Blair JD, Ikonomou MG, Kelly BC, Surridge B, Gobas FAPC (2009) Ultra-trace determination of phthalate ester metabolites in seawater, sediments and biota from an urbanized marine inlet by LC/ESI-MS/ MS. Environ Sci Technol 43:6262-6268

Cai QY, Mo CH, Zhu XZ, Wu QT, Wang BG, Cg J, HQ L (2003) Effect of municipal sludge and chemical fertilizers on phthalic acid esters (PAEs) contents in Ipomoea aquatica grown on paddy soils. Chin J Appl Ecol 14(11):2001-2005

Chen Q, Sun HW, Wang B, Hu GC (2004) Effects of di(2-ethylhexyl) phthalate (DEHP) on microorganisms and animals in soil. Agric Sci Technol 23:1156-1159

Chen M, Chen J, Tang C, Mao I (2008) The internal exposure of Taiwanese to phthalate - an evidence of intensive use of plastic materials. Environ Int 34:79-85

Constabel CP, Ryan CA (1998) A survey of wound- and methyl jasmonate-induced leaf polyphenol oxidase in crop plants. Phytochem 47:507-511

Constabel CP, Bergey DR, Ryan CA (1995) Systemin activates synthesis of wound-inducible tomato leaf polyphenol oxidase via the octadecanoid defense signaling pathway. PNAS 92:407-411

Dionisio-Sese ML, Tobita S (1998) Antioxidant responses of rice seedlings to salinity stress. Plant Sci 135:1-9

Ferreira A, Proenca C, Serralheiro MLM, Aráujo MEM (2006) The in vitro screening for acetylcholinesterase inhibition and antioxidant activity of medicinal plants from Portugal. J Ethnopharmacol 108:31-37

Fletcher JS, Muhitch MJ, Vann DR, Mc Farlane JC, Benenati FE (1985) Phytotox database evaluation of surrogate plant species recommended by the U.S. environmental protection agency and the organization for economic cooperation and development. Environ Toxicol Chem 4(4):523-532

Fornasiero RB (2001) Phytotoxic effects of fluorides. Plant Sci 161:979-985

Gao J (2010) Dynamic effects of PAEs on soil urease and phosphatase. Agric Sci Technol (in Chinese) 11:189-192

Gao J, Chen BQ (2008) The effect of microbes and change character of catalase in PAEs contaminated soil. J Soil Water Conserv 22:166169 (in Chinese) 
Giannopolitis CN, Ries SK (1977) Superoxide dismutases: II. Purification and quantitative relationship with water-soluble protein in seedlings. Plant Physiol 59:315-318

Guo Y, Kannan K (2012) Challenges encountered in the analysis of phathalate esters in foodstuffs and other biological matrices. Anal Bioanal Chem 404:2539-2554

Han Z, Hu Z (2005) Tolerance of Arundo donax to heavy metals. Chin J Appl Ecol 16:161-165

Hu XX, Han ZH, Liu BY, Zhang FB, Li F, Wang WH (2007) Distribution of phthalic acid esters in environment and its toxicity. Environ Sci Manag 32:37-40

Ingkaninan K, Temkitthawon P, Chuenchom K, Yuyaem T, Thongnoi W (2003) Screening for acetylcholinesterase inhibitory activity in plants used in Thai traditional rejuvenating and neurotonic remedies. J Ethnopharmacol 89:261-264

Koricheva J, Roy S, Vranjic JA, Haukioja E, Hughes PR, Hanninen O (1997) Antioxidant responses to stimulated acid rain and heavy metal deposition in birch seedlings. Environ Pollut 95:249-258

Kwak SS, Kim SK, Park IH, Liu JR (1996) Enhancement of peroxidase activity by stressed-related chemicals in sweet potato. Phytochem 43:565-568

Li ZS, Zhen RG, Rea PA (1995) 1-chloro-2,4-dinitrobenzene elicited increase in vacuolar glutathione- $S$-conjugate transport activity. Plant Physiol 109:177-185

Li CX, Fang ZQ, Zhang MS, Qin FX, Wu D, Lin Y (2010) Some areas investigation of phthalic esters in soil of Guizhou Province. Admin Tech Environ Monit 1:33-36

Liao CS, Yen JH, Wang YS (2009) Growth inhibition in Chinese cabbage (Brassica rapa var. chinensis) growth exposed to di- $n$ butyl phthalate. J Hazard Mater 163:625-631

Liu HR, Song HX, Liu DP, Guan CY, Liu Q, Chen SY (2007) Dynamics changes of soluble sugar and free amino acid contents in stem and leaf of different oilseed rape varieties. Acta Agr Boreali Occid Sin 16:123-126

Liu JJ, Lin SH, Xu PL, Wang XJ, Bai JG (2009a) Effects of exogenous Silicon on the activities of antioxidant enzymes and lipid peroxidation in chilling-stressed cucumber leaves. Agr Sci Chin 8:1075-1086

Liu WL, Shen F, Zhang Z, Zhang CB (2009b) Distribution of phthalate esters in soil of e-waste recycling sites from Taizhou city in China. Bull Environ Contam Toxicol 82:665-667

Ma TT, Teng Y, Christie P, Luo YM, Chen YS, Ye M, Huang YJ (2013) A new procedure combining GC-MS with accelerated solvent extraction for analysis of soils contaminated with phthalic acid esters. Front Environ Sci Eng 7:31-42

Mishra NP, Mishra RK, Singhal CS (1993) Changes in the activities of anti-oxidant enzymes during exposure of intact wheat leaves to strong visible light at different temperatures in the presence of protein synthesis inhibitors. Plant Physiol 102:903-910

Moya JL, Ros R, Picazo I (1993) Influence of cadmium and nickel on growth, net photosynthesis and carbohydrate distribution in rice plants. Photosynth Res 36:75-80

Nwosu TN, Palleschi G, Mascini M (1992) Comparative studies of immobilized enzyme electrodes based on the inhibitory effect of nicotine on choline oxidase and acetylcholinesterase. Anal Lett $25: 821-835$

Organization for Economic Cooperation and Development (1984) Terrestrial Plants: Growth Test, OECD guidance for testing of chemicals. No. 208. OECD, Paris

Pielichowska M, Wierzbicka M (2004) Uptake and localization of cadmium by Biscutella laevigata, a cadmium hyperaccumulator. Acta Biol Cracov Bot 46:57-63

Qu AJ, Guo LH, Sun XG, Zhu CM, Li YR, Yan KI (2006) Effects of pesticide stress on free proline and SOD content in Euonymus japonica. Agrochem 1:35-38
Rai V, Vajpayee P, Singh SN, Mehrotr S (2004) Effect of chromium accumulation on photosynthetic pigments, oxidative stress defense system, nitrate reduction, proline level and eugenol content of Ocimum tenuiflorum L. Plant Sci 167:1159-1169

Ren HX, Chen X, Wu DX (2001) Effects of elevated $\mathrm{CO}_{2}$ on photosynthesis and antioxidative ability of broad bean plants grown under drought condition. Acta Agr Sin 27:729-736

Schoner S, Krause GH (1990) Protective systems against active oxygen species in spinach: response to cold acclimation in excess light. Planta 180:383-389

Sharma SS, Dietz KJ (2005) The significance of amino acids and amino acid-derived molecules in plant responses and adaptation to heavy metal stress. J Exper Bot 57:711-726

Shu GP, Pontieri V, Dengler NG, Mets LJ (1999) Light induction of cell type differentiation and cell-type-specific gene expression in cotyledons of a C4Plant, Flaveria trinervia. Plant Physiol 121:731-741

Shukla UC, Joshi PC, Kakkar P (2002) Synergistic action of ultraviolet-b radiation and cadmium on the growth of wheat seedlings. Ecotoxicol Environ Saf 51:90-96

Starratt AN, Lazarovits G (1999) Herbicide-induced disease resistance and associated increases in free amino acid levels in melon plants. Can J Plant Pathol 21:33-36

Sundarammal S, Thirugnanasampandan R, Tamil Selvi M (2012) Chemical composition analysis and antioxidant activity evaluation of essential oil from Orthosiphon thymiflorus (Roth) Sleesen. Asian Pac J Trop Biomed 2:S112-S115

Szarek-Łukaszewska G, Słysz A, Wierzbicka M (2004) Response of Armeria maritima (mill.) willd. to $\mathrm{Cd}, \mathrm{Zn}$ and $\mathrm{Pb}$. Acta Biol Cracov Bot 46:19-24

Tan GH (1995) Residue levels of phthalate esters in water and sediment samples from the Klang River basin. Bull Environ Contam Toxicol 54:171-176

Treichel S, Brinckmann E, Scheitler B, yon Willert DJ (1984) Occurrence and changes of proline content in plants in the southern Namib Desert in relations to increasing and decreasing drought. Planta 162:236-242

Tsangaris C, Papathanasiou E, Cotou E (2007) Assessment of the impact of heavy metal pollution from a ferro-nickel smelting plant using biomarkers. Ecotoxicol Environ Saf 66:232-243

US Department of Agriculture (2011) Soil texture calculator. USDA, Washington, DC

US EPA (1996) Ecological effects test guidelines (OPPTS 850.4200): seed germination/root elongation toxicity test. US EPA, Washington, DC

Wagner M, Oehlmann J (2009) Endocrine disruptors in bottled mineral water: total estrogenic burden and migration from plastic bottles. Environ Sci Pollut Res 16:278-286

Wang XD, Sun C, Gao SX, Wang LS, Han SK (2001) Validation of germination rate and root elongation as indicator to assess phytotoxicity with Cucumis sativus. Chemosphere 44:17111721

Wang XT, Ma LL, Sun YZ, Xu XB (2006) Phthalate esters in sediments from Guanting Reservoir and the Yongding River, Beijing, People's Republic of China. Bull Environ Contam Toxicol 76:799-806

Wang CR, Tian Y, Wang XR, Geng JJ, Jiang JL, Yu HX, Wang C (2010) Lead-contaminated soil induced oxidative stress, defense response and its indicative biomarkers in roots of Vicia faba seedlings. Ecotoxicol 19:1130-1139

Wilhelm FD (2007) Reactive oxygen species, antioxidants and fish mitochondria. Front Biosci 12:1229-1237

Wong Z (2000) Plant physiology. China Agriculture Press, Beijing

Xie HJ, Shi YJ, Teng SX, Wang WX (2009) Impact of phthalic acid esters on diversity of microbial community in soil. Environ Sci Chin 30:1286-1291 
Xu YC, Li SH, Cai CL, Liu GJ, Chen SW (2001) Carbohydrate metabolism in source leaves of Jonagold apple tree under water stress and after water stress relief. J Fruit Sci 18:1-6

Xu G, Li FH, Wang QH (2008) Occurrence and degradation characteristics of dibutyl phthalate (DBP) and di-(2-ethylhexyl) phthalate (DEHP) in typical agricultural soils of China. Sci Total Environ 393:333-340

Yin R, Lin XG, Wang SG, Zhang HY (2002) Influence of phthalic acid esters in vegetable garden soil on quality of capsicum fruit. Agro Environ Prot 21:1-4

Yokota T (1997) The structure, biosynthesis and function of brassinosteroids. Trends Plant Sci 2:137-143

Zeng QY, Mo CH, Cai QY, Wang BG (2005) Uptake pathway of phthalic acid esters (PAEs) by Brassica parachinensis. Trans CSAE 21:137-141

Zeng QY, Mo CH, Cai QY, Wu QT (2006) Possible pathways through which phthalic in radish plants (Raphanus sativus) acid esters (PAEs) are accumulated. Acta Scientiae Circumstantiae 26:10-16

Zhang YX, Li XL (2003) Toxicity of three organophosphorus pesticides on Hordeum vulgare seedling. J Agro Environ Sci 22:754 757

Zhang HX, Xia Y, Wang GP, Shen ZG (2008) Excess copper induces accumulation of hydrogen peroxide and increases lipid peroxidation and total activity of copper-zinc superoxide dismutase in roots of Elsholtzia haichowensis. Planta 227:465-475

Zhang HX, Zhang FQ, Xia Y, Wang GP, Shen ZG (2010) Excess copper induces production of hydrogen peroxide in the leaf of Elsholtzia haichowensis through apoplastic and symplastic $\mathrm{Cu}$ Zn-superoxide dismutase. J Hazard Mater 178:834-843

Zhou J, Zhu XS, Cai ZH (2010) Tributyltin toxicity in abalone (Haliotis diversicolor supertexta) assessed by antioxidant enzyme activity, metabolic response, and histopathology. J Hazard Mater $183: 428-433$ 